\title{
MANAGING THE DREADED HELLP SYNDROME; CONVERTING LOSSES TO NEAR MISSES
}

\author{
Zubin Sheriar1, Sanjaykumar Patil2, Yamini Patil ${ }^{3}$
}

${ }_{1}^{1}$ Resident, Department of Obstetrics and Gynaecology, Krishna Institute of Medical Sciences, Hyderabad, Telangana. 2Professor, Department of Obstetrics and Gynaecology, Krishna Institute of Medical Sciences, Hyderabad, Telangana. ${ }^{3}$ Associate Professor, Department of Obstetrics and Gynaecology, Krishna Institute of Medical Sciences, Hyderabad, Telangana.

\section{ABSTRACT}

\section{BACKGROUND}

HELLP is a rare life-threatening obstetric syndrome. It is a multisystemic complication of preeclampsia occurring in 0.1 to $0.8 \%$ of all pregnancies and in $10 \%$ to $20 \%$ of those with severe preeclampsia/eclampsia. This dreaded condition was traditionally associated with high rates of perinatal mortality over $70 \%$ and maternal mortality over $25 \%$. However recent trends in early recognition and diagnosis, effective assessment and the rapid initiation of medical and obstetric critical care, all offer significant improvement in maternal and foetal prognosis.

Aims and Objectives- To analyse the incidence, maternal and neonatal outcome of HELLP syndrome in a tertiary care teaching hospital serving a semi urban and rural population and to study management solutions to reduce maternal and perinatal mortality.

\section{MATERIALS AND METHODS}

A retrospective descriptive study identified 20 cases of HELLP syndrome from a total of 4286 deliveries and 110 cases of severe preeclampsia (100 cases) and antepartum eclampsia (10 cases) over a one-year period. Important parameters assessed were predisposing factors, gestation at presentation, critical care, mode of delivery and maternal and perinatal outcomes.

\section{RESULTS}

The mean maternal age was 23.8 years with severe preeclampsia diagnosed in 17 and eclampsia in 3 cases. The syndrome manifested in 16 cases at a mean gestational age of 34.5 weeks and postnatally in 4 cases. The average platelet was 42000 with elevated liver enzymes in all and increased creatinine in 14 cases. An average of 5 units of FFPs and 3 units of platelets were infused. 8 women had vaginal deliveries and 12 had caesarean sections. There were 4 maternal deaths, 2 stillbirth and 4 neonatal deaths.

\section{CONCLUSION}

In spite of being a tertiary referral centre the potential maternal loss related to the HELLP syndrome was converted to a maternal near miss in a majority of cases. Identification, obstetric critical care management with adequate blood products, appropriate delivery and advanced neonatal care all worked to improve the final outcomes for the mother and her neonate, a truly satisfying result for the multispecialty clinical team.

\section{KEYWORDS}

HELLP Syndrome, Obstetric Emergency, Near-Miss.

HOW TO CITE THIS ARTICLE: Sheriar Z, Patil S, Patil Y. Managing the dreaded HELLP syndrome; converting losses to near misses. J. Evolution Med. Dent. Sci. 2018;7(17):2138-2140, DOI: 10.14260/jemds/2018/478

\section{BACKGROUND}

The acronym HELLP was coined by Weinstein in 1982 to describe a syndrome consisting of Hemolysis, Elevated Liver enzymes \& Low Platelet count. The syndrome is characterized by hepatic endothelial disruption followed by platelet activation, aggregation \& consumption, ultimately resulting in ischemia \& hepatocyte death. The spectrum of disease resulting from pathophysiology of preeclampsia continues to challenge diagnostic accuracy of clinicians.[1] The onset of HELLP Syndrome is rapid, variable and sometimes atypical, so the diagnosis is generally delayed for 5-7 days. Many of them are misdiagnosed with disorders, like cholecystitis, oesophagitis, gastritis, hepatitis, viral fever or

'Financial or Other Competing Interest': None.

Submission 15-03-2018, Peer Review 08-04-2018,

Acceptance 14-04-2018, Published 23-04-2018.

Corresponding Author:

Dr. Zubin Sheriar

\#15, Summer Breeze,

$15^{\text {th }}$ Road, Bandra (W),

Mumbai-400050, Maharashtra.

E-mail: zubinsheriar@gmail.com

DOI: $10.14260 /$ jemds $/ 2018 / 478$ idiopathic thrombocytopenia. Typical clinical symptoms are right upper quadrant pain abdomen or epigastric pain, nausea and vomiting. Pain abdomen may be colicky, intermittent associated with malaise few days before actually diagnosing it to be HELLP Syndrome.

\section{Incidence}

HELLP develops in approximately 0.1 to $0.8 \%$ of pregnancies overall. Occurs in 10 to $20 \%$ of women with severe preeclampsia and eclampsia. With 15 to $20 \%$ of HELLP syndrome not associated with antecedent hypertension or proteinuria it is suggested that HELLP is a separate disorder from preeclampsia.[2]

\section{Aims \& Objectives}

The aim of the study was to analyse the incidence, maternal and neonatal outcome of HELLP syndrome managed at a tertiary care hospital serving a large rural population. In addition to this also referrals for critical obstetric care from public and private sector were analysed. To identify working solutions to reduce maternal \& perinatal mortality \& morbidity in this semirural setting is one of the most important objectives. 


\section{MATERIALS AND METHODS}

This was a retrospective descriptive study done in Krishna Institute of Medical Sciences, Karad for a period of 12 months, including 110 cases of severe preeclampsia and Eclampsia, out of which 20 cases developed HELLP Syndrome.

\section{Inclusion Criteria}

- Women with severe preeclampsia and Eclampsia>28 weeks with abnormal laboratory findings.

- Women with severe hypertension from more than 28 weeks gestation.

The selected cases were studied with history, clinical data and detailed laboratory investigations done including complete haemogram, coagulation profile, liver profile, renal profile values which have been recorded and HELLP Syndrome cases were diagnosed accordingly.

\section{Diagnostic Laboratory Investigations}

Liver enzymes and Bilirubin were elevated in all 20 cases (100\%). Average SGOT is $116 \mathrm{U} / \mathrm{L}$ and SGPT is $130 \mathrm{U} / \mathrm{L}$. Average Indirect bilirubin is $1.9 \mathrm{mg} / \mathrm{dL}$. Thrombocytopenia is present in all the cases $(100 \%)$. The average platelet count is 42000/ul (Range 30000 to 75000). INR was raised in all 20 cases $(100 \%)$. In 14 of the 20 cases (70\%) Serum Creatinine is elevated with an average of $1.6 \mathrm{mg} / \mathrm{dL}$.

\section{Antihypertensives \& Blood Products}

Nifedipine and Labetalol were the drugs of choice used for antihypertensive management. Magnesium Sulphate therapy was administered in 8 out of the 20 cases (40\%) for patients who had eclampsia and also those who showed imminent signs of eclampsia. Parenteral steroids were administered to the antenatal cases which were 16 of the $20(80 \%)$. Blood products were administered in all cases (100\%). On average 2 units of Packed cells, 5 units of Fresh Frozen Plasma and 3 units of platelets were administered.

A maternal near-miss case is defined as "a woman who nearly died but survived a complication that occurred during pregnancy, childbirth or within 42 days of termination of pregnancy" [3]. In practical terms, women are considered near-miss cases when they survive life-threatening conditions.

In practice we strive to convert maternal deaths into maternal near-miss cases. It is important to assess the outcome by analysing how to do this and save as many lives as we can. As HELLP Syndrome is a life-threatening condition, those cases which survive are considered near-miss cases.

\section{Statistical Analysis}

- $\quad$ All statistical analysis was done using MS-Excel 2010

- Descriptive data was presented as percentages

\section{RESULTS}

Of 100 cases of Preeclampsia, 17 cases (17\%) developed HELLP syndrome and out of 10 cases of Eclampsia, 3 cases (30\%) had HELLP Syndrome. The present study showed $4.4 \%$ maternal mortality. i.e. 4 maternal deaths.

Out of the 20 cases $12(60 \%)$ were emergency cesarean sections, 4 (20\%) were vaginal deliveries and 4 cases $(20 \%)$ were post vaginal deliver transfers from other centers. In all 20 cases MICU admissions were required. In 14(70\%) of those cases intubation with continuous airway pressure ventilation was required. There was a maternal mortality in 2 cases $(10 \%)$ due to hemorrhagic shock. There was a LAMA discharge in 6 cases post-delivery (30\%) out of which there was a maternal mortality in 2 cases after discharge.

\section{Details of Study \& Patient Profiles}

Out of 4286 deliveries over a period of 12 months 20 cases out of 110 cases of Severe Preeclampsia and Eclampsia were diagnosed with HELLP syndrome. Average age of the patients was 24 years (Range - 21 to 31 years). 14 of the 20 cases (70\%) were Primigravidae and 6 cases (30\%) were Multiparas. 4 patients were registered antenatally (20\%), 12 were referred from other centres (60\%) and 4 were unregistered walk ins (20\%). The average gestational age of presentation was 34.7 weeks (Range 30 to 40 weeks). 16 patients were diagnosed with HELLP syndrome antenatally (80\%) and 4 were diagnosed postnatally (20\%).

\section{Neonatal Outcome \& NICU Care}

Neonatal outcome is also a very important factor as we as obstetricians deal with two lives and not one. With sufficient NICU facilities neonates delivered at a preterm period also have a very good chance of surviving.

In 18 cases there were live births (90\%) while there was an intra uterine foetal death in 2 cases (10\%). 4 babies were transferred to mother side (25\%) and 14 were transferred to the NICU (75\%). All the 14 babies were transferred for preterm care with an average birth weight of $1.5 \mathrm{~kg}$ (Range $1.1 \mathrm{~kg}$ to $1.9 \mathrm{~kg}$ ). Exogenous surfactant therapy was used in all 14 cases. There were mortalities in 4 cases $(25 \%)$ due to respiratory distress.

\section{DISCUSSION}

HELLP Syndrome is a life-threatening complication considered to be a severe variant of Preeclampsia and Eclampsia. The incidence of HELLP Syndrome in the present retrospective study is $18.1 \%(20 / 110$ cases $)$ which is comparatively higher, than in the study of ${ }^{[4]}$ Sowjanya et al $15.5 \%$ and $6.5 \%$ in the study of ${ }^{[5]}$ Ara $S$ et al. This may be due to better facilities in the concerned area.

16 of the 20 cases $(80 \%)$ were antepartum which was slightly higher than in Ara S et al 75\%.

The neonatal deaths were 4 cases $(20 \%)$ in comparison to Sibai BM (33.3\%),[6] Magann EF et al (23.2\%),[7] Liu et al $(42 \%),{ }^{[8]}$ Visser W (14.1\%) ${ }^{[9]}$ and Sowjanya et al (35.33\%).

Caesarean Section rate in the present study was $60 \%$ comparable to $71 \%$ of Vigil de Gracia $\mathrm{P}^{[10]}$ and $63 \%$ of Haddad B et al.[11]

\section{CONCLUSION}

Early registration and regular antenatal check-ups play a major role in early diagnosis and classification of HELLP Syndrome. Availability of better transport facilities and prompt referral is essential. HELLP Syndrome must be treated in tertiary care centre as it is one of the dreadful obstetric complication which needs multidisciplinary team approach, availability of life saving facilities like mechanical ventilators, dialysis equipment and blood products neonatal care facilities. For this reason, obstetrician at any level should be attentive, alert and need to improve quality care and make efforts for early identification even at its atypical 
presentation and should be able to provide skilled management techniques till the case is shifted to tertiary care centre. The Global mortality rate of HELLP Syndrome has been reported to be as high as $25 \%$. That's why it is critical for expecting mothers to be aware of the condition and its symptoms, so they can receive early diagnosis and treatment. Doctors should enhance their skills in antenatal care to identify high risk factors at primary health centre and community health centre.

\section{Strategies for Success}

- Initial steps should be taken to stabilize the mother, assess the foetal condition \& decide whether prompt delivery is indicated.

- Severe hypertension can be treated with antihypertensives \& MgSO4 to prevent convulsions \& for neuroprotection.

- $\quad$ For pregnancies $\geq 34$ weeks of gestation delivery rather than expectant management is preferred. (Grade 1C).[12]

- Potential risks of preterm birth are outweighed by the risks associated with HELLP syndrome. ${ }^{[13]}$

- For pregnancies $<34$ weeks with maternal \& foetal status are reassuring, delivery after a course of corticosteroids to accelerate foetal pulmonary maturity is preferred. (Grade 2C).[14]

- Although the lab abnormalities of HELLP will reverse in a subgroup managed expectantly \& serious maternal complications are uncommon with careful maternal monitoring, overall perinatal outcome is not improved

- No benefit of dexamethasone for treatment of HELLP syndrome has been proven. (Grade 1B).[15]

\section{Strategic Advantages Supporting Success}

- Tertiary care institution with multispecialty care.

- Well-developed MICU \& obstetric critical care.

- Lab work available in house around the clock.

- Accredited blood bank with adequate blood products.

- Evidence based antihypertensive therapy, $\mathrm{MgSO}_{4}$ \& antenatal steroids.

- Appropriate mode of early delivery.

- Well equipped \& staffed NICU.

\section{REFERENCES}

[1] Buist NRM, Winter SC. HELLP syndrome. JAMA 1999;281(8):703-5.

[2] Sibai BM, Taslimi MM, el-Nazer A, et al. Maternalperinatal outcome associated with the syndrome of hemolysis, elevated liver enzymes, and low platelets in severe preeclampsia-eclampsia. Am J Obstet Gynecol 1986;155(3):501-9.

[3] Say L, Souza JP, Pattinson RC. Maternal near misstowards a standard tool for monitoring quality of maternal health care. Best Pract Res Clin Obstet Gynaecol 2009;23(3):287-96.

[4] Sowjanya K, Bhavani, Himabindu, et al. Clinical Study on HELLP syndrome - maternal and perinatal outcome. IOSR Journal of Dental and Medical Sciences 2016;15(1):71-6.

[5] Ara S, Singh BB, Birla N, et al. Incidence of HELLP syndrome in pre-eclampsia and eclampsia and maternal and perinatal outcome including morbidity and mortality. Indian Journal of Research 2015;4(7):65-7.

[6] Sibai BM, Ramadan MK, Chari RS, et al. Pregnancies complicated by HELLP syndrome (hemolysis, elevated liver enzymes, and low platelets): subsequent pregnancy outcomes and long term prognosis. Am J Obstet Gynecol 1995;172(1 Pt 1):125-9.

[7] Martin JN, Rinehart BK, May WL, et al. The spectrum of severe preeclampsia: comparative analysis by HELLP (hemolysis, elevated liver enzyme levels, and low platelet count) syndrome classification. Am J Obstet Gynecol 1999;180(6 Pt 1):1373-84.

[8] Liu CM, Chang SD, Cheng PJ, et al. Comparisons of maternal and perinatal outcomes in Taiwanese women with complete and partial HELLP syndrome and women with severe preeclampsia without HELLP. J Obstet Gynaecol Res 2006;32(6):550-8.

[9] Visser W, Wallenburg HC. Temporising management of severe preeclampsia with and without HELLP syndrome. Br J Obstet Gynaecology 1995;102(2):1117.

[10] Vigil-De Gracia P. Pregnancy complicated by preeclampsia-eclampsia with HELLP syndrome. Int J Gynecol Obstet 2001;72(1):17-23.

[11] Haddad B, Barton JR, Livingston JC, et al. Risk factors for adverse maternal outcomes among women with HELLP (hemolysis, elevated liver enzyme levels, and low platelet count) syndrome. Am J Obstet Gynecol 2000;183(2):444-8.

[12] Visser W, Wallenburg HC. Maternal and perinatal outcome of temporizing management in 254 consecutive patients with severe preeclampsia remote from term. Eur J Obstet Gynecol Reprod Biol 1995;63(2):147-54.

[13] Sibai BM. HELLP. UpToDate 2016.

[14] Sibai BM, Barton JR. Dexamethasone to improve maternal outcome in women with hemolysis, elevated liver enzymes, and low platelets syndrome. Am J Obstet Gynecol 2005;193(5):1587-90.

[15] Woudstra DM, Chandra S, Hofmeyr GJ, et al. Corticosteroids for HELLP (hemolysis, elevated liver enzymes, low platelets) syndrome in pregnancy. Cochrane Database Syst Rev 2010;(9):CD008148. 